\title{
New Insights into the Mechanisms and Sites of Action of Lamotrigine
}

\author{
J.M. Langoscha ${ }^{\text {a }}$ X.-Y. Zhou ${ }^{\text {a }}$ H. Grunze ${ }^{b}$ J. Walden ${ }^{\mathrm{a}}$ \\ aDepartment of Psychiatry, University of Freiburg Medical School, Freiburg i.Br., and ${ }^{\mathrm{b}}$ Department of Psychiatry, \\ University of Munich, Germany
}

\section{Key Words}

CA1 - Epilepsy · Field potentials · Guinea pig ·

Hippocampus · Lamotrigine · Synaptic transmission amino acids [5, 6]. Furthermore, antagonistic effects of LTG on calcium channels have been found in rat cortical neurons and in the CA1/CA3 hippocampal area of guinea pigs $[7,8]$.

\section{Methods}

Hippocampal slices were prepared as described previously. For preparation of concentration response curves, LTG was applied for $30 \mathrm{~min}$, and the maximum change was measured. Each concentration was used on one slice only. The CA1 region of the hippocampus was identified by transmission microscopy and glass microelectrodes filled with $3 \mathrm{M} \mathrm{NaCl}$ were used to detect population spikes and fEPSP in the pyramidal cell layer or in the dendritic region of CA1, respectively. Test stimuli were generated by isolated pulse stimulators. Field potential changes (fEPSP and population spikes) were evoked by constant stimulation $(f=0.066 \mathrm{~Hz}$, duration $50 \mu \mathrm{s}, I=$ 0.8-4 mA) with an insulated bipolar tungsten electrode, placed in the stratum radiatum of CA1. The intensity of test stimulation was adjusted to evoke two thirds of maximal fEPSP or population spikes, respectively.

\section{Results}

The concentration response curves showed different actions of LTG in concentrations near therapeutic plasma levels $(10 \mu M)$ on fEPSP and population spikes. The initial slopes of fEPSP were not affected, whereas the ampli- to block presynaptic voltage-sensitive sodium channels, which results in an inhibition of the release of excitatory

\begin{tabular}{ll}
\hline KARGER & ( 2000 S. Karger AG, Basel \\
Fax +4161306 1234 342 X00/0425-0026\$17.50/0 \\
$\begin{array}{l}\text { E-Mail karger@karger.ch } \\
\text { www.karger.com }\end{array}$ & $\begin{array}{l}\text { Accessible online at: } \\
\text { www.karger.com/journals/nps }\end{array}$
\end{tabular}

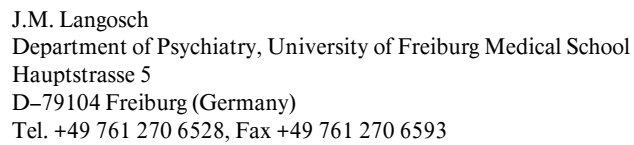

Department of Psychiatry, University of Freiburg Medical School

D-79104 Freiburg (Germany)

Tel. +49761270 6528, Fax +497612706593 
tudes of population spikes were significantly decreased by $15.1 \pm 4.2 \%$. Higher concentrations of LTG decreased both fEPSP slopes and population spikes amplitudes; however, effects on population spikes were much stronger. Those effects were reversible after a 30-min wash-out period.

\section{Discussion}

The release of excitatory amino acids from presynaptic sites of the synaptic cleft as well as antagonistic actions on the various glutamate receptors are possible targets for drugs modulating synaptic transmission and excitability in the CA1 region of the hippocampus. LTG is believed to block voltage-sensitive sodium channels with a resulting decrease in glutamate release $[5,6]$. The measurement of fEPSP may provide some evidence for a suspected modulation of synaptic transmission by LTG. Our experiments do not show any change in the slope of fEPSP at concentrations up to $10 \mu M$ LTG. Therefore, no significant influence on the neurotransmitter release can be presumed in this concentration range. However, $10 \mu M$ LTG is a concentration that clearly affects amplitudes of population spikes. A concentration of $10 \mu M$ LTG in our experimental setting corresponds to estimated therapeutic plasma levels of about 4-16 $\mu \mathrm{M}$ in humans, especially if $55 \%$ plasma protein binding is taken into account [9]. We have found effects of LTG on neurotransmitter release only for concentrations far above the pharmacologically relevant ones. However, at these concentrations, effects of LTG on population spikes were much stronger than on fEPSP. This is in contradiction to previous reports and may be due to higher concentrations or a pharmacologically induced transmitter release in those studies $[5,10$, 11].

Measurements of population spikes are important in understanding the effects of LTG on the integration of synaptic signals into a neuronal output. Possible mechanisms for the decrease of population spike amplitudes reported here are well-known inhibitions of voltagedependent sodium channels [12-14] and antagonistic effects of LTG on calcium channels [7, 8] or modulation of transient potassium outward currents as recently reported [15]. This might explain a reduced neuronal excitability and antiepileptic effects of LTG.

In conclusion, our experiments reveal different effects of LTG on synaptic transmission and on postsynaptic neuronal sites, whereas in the range of therapeutic plasma levels, synaptic transmission was unaffected.

\section{Acknowledgment}

The study was supported in part by the Vada and Theodore Stanley Foundation.

\section{References}

1 Bialer M, Johannessen SI, Kupferberg HJ, Levy RH, Loiseau P, Perucca E: Progress report on new antiepileptic drugs: A summary of the Third Eilat Conference. Epilepsy Res 1996; 25:299-319.

2 Yuen AWC: Lamotrigine: A review of antiepileptic efficacy. Epilepsia 1994;35:S33-S36.

3 Calabrese JR, Rapport DJ, Shelton MD, Kimmel SE: Clinical studies on the use of lamotrigine in bipolar disorder. Neuropsychobiology 1998:38:185-191.

4 Post RM, Frye, MA, Denicoff KD, Leverich GS, Kimbrell TA, Dunn, RT: Beyond lithium in the treatment of bipolar illness. Neuropsychopharmacology 1998;19:206-219.

5 Leach MJ, Marsden CM, Miller AA: Pharmacological studies on lamotrigine, a novel potential antiepileptic drug. II. Neurochemical studies on the mechanism of action. Epilepsia 1986; 27:490-497.
6 Messenheimer JA: Lamotrigine. Epilepsia 1995;39:S87-S94.

7 Stefani A, Spadoni F, Siniscalchi A, Bernardi G: Lamotrigine inhibits $\mathrm{Ca}^{2+}$ currents in cortical neurons: Functional implications. Eur J Pharmacol 1996;307:113-116.

8 v. Wegerer J, Hesslinger B, Berger M, Walden $\mathrm{J}$ : A calcium antagonistic effect of the new antiepileptic drug lamotrigine. Eur Neuropsychopharmacol 1997;7:77-81.

9 Peck AW: Clinical pharmacology of lamotrigine. Epilepsia 1991;32:S9-S12.

10 Lamb RJ, Leach MJ, Miller AA: Anticonvulsant profile in mice of lamotrigine, a novel anticonvulsant. Br J Pharmacol 1985;85:366P.

11 Leach MJ, Baxter MG, Critchley MAE: Neurochemical and behavioural aspects of lamotrigine. Epilepsia 1991;32:S4-S8.
12 Cheung H, Kamp D, Harris E: An in vitro investigation of the action of lamotrigine on neuronal voltage-activated sodium channels. Epilepsy Res 1992;13:107-112.

13 Xie X, Lancaster B, Peakman T, Garthwaite J: Interaction of the antiepileptic drug lamotrigine with recombinant rat brain type IIA $\mathrm{Na}^{+}$ channels and with native $\mathrm{Na}^{+}$channels in rat hippocampal neurons. Pflügers Arch Eur J Physiol 1995;430:437-446.

14 Zona C, Avoli M: Lamotrigine reduces voltagegated sodium currents in rat central neurons in culture. Epilepsia 1997;38:522-525.

15 Grunze H, Greene RW, Möller HJ, Meyer T, Walden J: Lamotrigine may limit pathological excitation in the hippocampus by modulating a transient potassium outward current. Brain Res 1998;791:330-334. 